\title{
Developing cognitive task analysis and the importance of socio- cognitive competence/insight for professional practice
}

\author{
Julie Gore ${ }^{1}$ - Adrian P. Banks ${ }^{2}$ - Almuth McDowall ${ }^{3}$ \\ Received: 31 December 2017 / Accepted: 23 June 2018 / Published online: 4 July 2018 \\ (c) The Author(s) 2018
}

\begin{abstract}
Accelerating the cognitive expertise of professionals is a critical challenge for many organizations. This paper reports a collaborative, longitudinal, academic practitioner project which aimed to elicit, document, and accelerate the cognitive expertise of engineering professionals working with the manufacture and management of petroleum additives. Twenty-five engineering experts were trained by three academic psychologists to use applied cognitive task analysis (ACTA) interview techniques to document the cognition of their expert peers. Results had high face validity for practitioners who elicited hot/ sensory-based cognition, a number of perceptual skills and mental models, highlighting undocumented context specific expertise. We conclude from a peer review of findings, combined with experienced CTA analysts that ACTA techniques can be advanced in context by the explicit recognition and development of socio-cognitive competence/insight.
\end{abstract}

Keywords Cognitive task analysis · Training · Socio-cognitive insight

\section{Introduction}

Accelerating learning by capturing, documenting, and utilising professional cognitive expertise where technological excellence is fundamental to success is a critical challenge for many high-reliability, global organizations. As Hoffman et al. (2014) highlight, Goffee and Jones (2007, p 1) state that if an organization was able to document embedded knowledge from their clever people's minds-all it would need is an improved knowledge-management system. Failing to capture such tacit knowledge that they argue is one of the greatest disappointments of knowledge management initiatives.

The naturalistic decision-making (NDM) community has reported the advantages of applied cognitive task analysis (ACTA) and associated cognitive task analysis (CTA) techniques (Hoffman and Militello 2008; Roth 2008; Militello et al. 2010) for capturing and developing our insight

Julie Gore

j.gore@bath.ac.uk

1 School of Management, University of Bath, Bath BA2 7AY, UK

2 University of Surrey, Guildford, UK

3 Birkbeck College, University of London, London, UK of cognition. Notably, these techniques have also begun to steadily grow in other research areas of organizational behaviour and management practice (Gore and Ward 2017; Gore and McAndrew 2009; McAndrew and Gore 2012, 2013; Gore et al. 2015a, b, c; Osland 2010; Osland et al. 2013).

Tofel-Grehl and Feldon (2013) have also noted the growing popularity of cognitive task analysis (CTA) in both research and practice, and completed a meta-analysis of studies to examine the value of such training. They report that though their meta analysis is limited due to its small number of studies, the effect of CTA instruction is large (Hedges's $g=0.871$ ) Reports which focus upon the training of practitioners to adopt such techniques, however, are less well documented (Gore et al. 2015a, b, c; Potworowski and Green 2016). The work presented here, therefore, continues to examine the importance of the role of academics translating methodological research developments for impact and exploration of and in knowledge management practice (Anderson 2007; Gore and Conway 2016). In addition, we aimed to ensure that aspects of cognitive expertise that are difficult to articulate are documented with clear application validity. 


\section{Unpacking expertise}

Researchers have endeavored to uncover the concept of expertise for several decades through laboratory-based examination and naturalistic investigation (Ericsson and Smith 1991; Feltovich et al. 1997), exemplified by the naturalistic decision-making (NDM) framework, eliciting that experts learn in four ways (Koehler and Harvey 2004):

1. engaging in deliberate practice, often setting goals, and criteria for evaluation;

2. compiling extensive experience banks;

3. obtaining feedback that is accurate, and timely;

4. enriching their experiences by reflecting on their experience and lessons learnt from mistakes.

Several categories of knowledge discriminate experts from others, including novices, as both declarative ("what" static knowledge is known) and procedural knowledge ("how to" complete a task), are more apparent in experts who draw from a wide personal knowledge base. In addition, strong perceptual skills are purported as another essential component of expertise (Klein and Hoffman 2008); these include mental models; adept sense making of associations; the ability to run mental simulations. Such enriched mental models enable experts to spot anomalies and problems quickly and formulate information seeking tactics to manage uncertainty. NDM research further suggests that experts' metacognitive processes ensure that they take into account their own individual strengths and limitations when processing information and generating knowledge (Ward et al. 2018).

Hence, the primary aim of this project was to document to what extent CTA training and participating with, in this instance, ACTA would enable professionals to share their expertise-based cognition. Notably, we offer suggestions for adapting and improving the CTA methods for management practitioners and highlight the importance of developing socio-cognitive competence. ${ }^{1}$ This latter area, as yet, has been unexplored and echoes Hoffman et al. (2014) call for further explorations of the social aspects of CTA. We also note the importance of translating the findings from CTA for knowledge management, future scenario planning, and management learning development.

\footnotetext{
${ }^{1}$ Socio-cognitive competence refers here to the integration of cognitive and social properties required when complex cognitive and social features of a task are connected and require development.
}

\section{Organizational context}

The participants' workplace is a global organization in the formulation, manufacture, and marketing of petroleum additives for lubricants and fuels with a long history of innovation in decision-making. The organization has effectively used scenario planning for more than 45 years (see Wilkinson and Kupers 2013 for a recent review) initially through facilitated dialogue in which managers' assumptions could safely be shared, questioned, and challenged and subsequent focus on the strategic. Scenario practice in part of the organization began by exposing and questioning the future and facilitated dialogue in which managers' assumptions could safely be shared, questioned, and challenged. Many business units and different organizational functions besides strategy and finance went on to develop scenarios which focussed upon the big picture. In the 1980s, however, a refocus was required which concentrated on 'deep listening' to uncover uncertainties, probing the core concerns of leaders. At this time, more than 100 one-to-one interviews were completed with petroleum executives, each lasting 3-4 h. This approach has continued and is reported as being effective with the vast majority of the resultant scenarios being shared across the organization. Scenarios have continued to evolve and scenario developers aim to keep scenarios relevant and challenging learning tools which have impact upon organizational thinking and cognition.

This work has also had a renaissance outside the organization with many companies expecting to use scenario planning to add value via (1) an enhanced capacity to perceive change, and to (2) interpret and respond to change, (3) to influence other actors, and (4) enhance the capacity for organizational learning. Scenario planning continues to help shape-related global thinking and has had a huge influence on how businesses, governments, and organizations think about the future (Wilkinson and Kupers 2013, p 121).

Set within this innovative organizational culture, the authors were invited to explore within a much wider organizational project on knowledge management, how best expert cognition in engineering expertise could be elicited, documented, and shared, aiming to provide knowledge which would accelerate novice engineers' complex cognitive decision-making processes. The organization examined here was concerned with capturing expertise at the level of the individual. A key challenge was to ensure the practitioners' accurately captured cognition to maintain continuous knowledge transfer within this highly qualified workforce. This paper documents the process of training transfer and provides illustrative results of an engineering practitioner's ACTA. The expert cognition associated with managing 
uncertainty is highlighted (Lipshitz and Strauss 1997) and aspects of hot $/$ sensory $^{2}$-based cognition explored.

\section{Applied cognitive task analysis}

The ACTA technique is intended to support the identification of the key cognitive elements required to perform a task proficiently, albeit in a way useful to practitioners (Militello and Hutton 1998). As previously discussed in a research methods note to the psychological academic and practitioner community (Gore and McAndrew 2009), pragmatic work has successfully used ACTA to understand expertise in a wide range of areas including: fire fighting (Klein et al. 1989) recruitment, (Gore and Riley 2004), weather forecasting (Hoffman et al. 2006), clinical medical contexts (Militello and Hutton 1998; Militello et al. 1997), aviation and command and control operating procedures within naval and military environments (Drury and Darling 2008), and financial decision-making (McAndrew et al. 2009; McAndrew and Gore 2010, 2012, 2013). Crandall, Klein, Hoffman, Militello, and other researchers in the NDM community have adapted these methods, assisting knowledge transfer and training amongst expert domains. Such rigorous development has provided professionals with domain contextualised knowledge based on extensive real-life scenarios (Hoffman 1992; Klein and Crandall 1995; Schraagen et al. 2000, 2008). This has meant that training for cognitively demanding tasks within domainspecific areas has more explicitly documented tacit knowledge, skills, and expertise-based professional practice. Gore (2013) has previously argued that the ACTA techniques are evidence-based insights (Briner and Rousseu 2011) into domain-specific knowledge which is unlikely to be documented in the conventional training programmes. Within the management literature, evidence-based management encourages practitioners to use scientific information and stakeholder expertise to make more informed judgments about decision-making. Hence, the type of knowledge elicited by the ACTA techniques is often undocumented experiential, evidence-based insights.

Whilst much of the work completed in judgment and decision-making has a history of examining the cognitive errors associated with decision-making (Kahneman et al. 1982), the theoretical origins of the decision-making perspective adopted in this study focus on real-world decisionmaking, i.e., naturalistic decision-making (NDM) (Klein et al. 1993). This perspective emphasises expertise, positive aspects of cognition and the study of expert intuition.

\footnotetext{
${ }^{2}$ Hot/sensory-based cognition to usually associated with cognition as a result of emotions (hot and cold) and, or sensory, i.e., elicited from the senses including sight and smells.
}

The cognitive areas ACTA aims to examine in depth are: (1) difficult judgments and decisions; (2) attentional demands; (3) critical cues and patterns; (4) problem solving strategies (2009). The ACTA methods are distinct from other techniques which explore tacit cognitive processes as they employ a range of knowledge elicitation and representation techniques that logically progress, combining the elicitation of task-specific, expertise-based knowledge. ACTA's knowledge representation techniques deliver a systematic schematic for arranging and juxtaposing cognitive information (cognitive mapping), whilst the knowledge elicitation techniques comprise of in-depth interviews (and occasionally observations).

\section{Method}

After assessing organizational needs via a pilot study stage, one of this studies included first day $(7 \mathrm{~h}$ ) briefing about the use of ACTA techniques which was provided for a small group of professionals with different areas of engineering expertise. During a second day, one of the authors trained three engineers to use a selection of the ACTA techniques (7 h) (Militello and Hutton 1998).

Stage two: a 3 day longitudinal $(21 \mathrm{~h})$ training event completed over 3 months was provided by the authors/ CTA instructors for engineering professionals $(N=22,5$ female, 17 male). The professionals had a range of engineering expertise in management, manufacturing technology, finance, human resources, information technology, product development, and operation management. Many of the participants were senior research scientists educated to doctoral level, all with 5-15 years of domain-specific experience (domain experts).

\subsection{Procedure-training the participants}

First, the researchers completed a task diagram and knowledge audit to illustrate the interview techniques associated with stage one and two of ACTA. This process was stopped and re-started in order for the engineers to ask questions and clarify the process. The first stage of ACTA, the production of a task diagram, provides the interviewer with a broad overview of the task. This interview helps to identify areas requiring complex cognitive skills which can be examined in depth in stage 2 of the process: the knowledge audit. Task diagrams were completed for key areas of engineering work involving cognitive complexity to identify elements seen as essential by the expert engineers. The researchers prior need analysis which had documented that such information was not currently documented meaningfully in training procedures, but that this was potentially vital to train and induct novice engineers. The next step was an in-depth interview 
Table 1 Knowledge audit probes. Adapted from Militello and Hutton (1998)

Past and future: experts know how the situation developed and know where the situation is going (de Groot 1946/1978; Endsley 1995; Klein and Crandall 1995; Klein and Hoffman 1993): Is there a time when you walked into the middle of a situation and knew exactly how things got there and where they were headed?

Big picture: experts understand the whole situation and understand how elements fit together (Endsley 1995; Klein 1997): Can you give me an example of the big picture for this task? What are the major elements you have to know and keep track of?

Noticing: experts can detect cues and see meaningful patterns (de Groot 1946/1978; Klein and Hoffman 1993; Shanteau 1985): Have you had experiences where part of a situation just 'popped' out at you; where you noticed things going on that others did not catch? What is an example?

Tricks of the trade/Job smarts: experts can combine procedures and do not waste time and resources (Gore 2004; Klein and Hoffman 1993): When you do this task, are there ways of working smart or accomplishing more with less, i.e., tricks of the trade-that you have found particularly useful?

Improvising/opportunities: experts can see beyond standard operating procedures and take advantage of opportunities (Dreyfus and Dreyfus 1986; Shanteau 1985): Can you think of an example when you have improvise in this task or noticed an opportunity to do something better?

Self-monitoring: experts are aware of their own performance and notice when performance is not what it should be and adjust to get the job done (Cohen et al. 1996; Glaser and Chi 1988): Can you think of a time when you realized that you would need to change the way that you were performing to get a job done?

Anomalies: experts can spot the unusual and detect deviations from the norm (Klein et al. 1989; Klein 1997; Klein and Hoffman 1993): Can you describe an instance where you spotted a deviation from the norm, or knew something was amiss?

Equipment difficulties: experts know that equipment can mislead and do not implicitly trust equipment as novices might (Cannon-Bowers et al. 1993): Have there been times when the equipment pointed in one direction, but your own judgment told you to do something else? Or when you had to rely on experience to avoid being led astray by the equipment?

process conducted between participants, the researchers acting as observers and facilitators as necessary.

The interviewers' (practitioner engineers') began by asking the interviewees (expert engineers) to break down a cognitive task related to their expert job role into three-to-six steps. These steps/stages were documented by a cognitive map showing three-to-six connecting nodes/circles which relate to the task. The interviewer then asks which step/ stage of the task is most cognitively challenging and why, maybe, novices find this difficult. This first stage can take up to $30 \mathrm{~min}$ to complete. The interviewer is encouraged to check on understanding with the expert to ensure that she or he agrees that the task diagram accurately provides a broad overview of the task. Together, the interviewer and interviewee identify which element of the task is most cognitively complex and takes most thinking, judgment, and decision-making. This stage of the task is then explored and probed in great detail by completing stage two of ACTA, the Knowledge audit.

Second, the engineers practiced Knowledge Audit techniques with each other and documented their understanding of complex cognition. Again, a stop-start approach was adopted to facilitate the question technique and the documentation of knowledge elicited. The knowledge audit focuses upon a cognitive sub-task elicited from the task diagram and is well documented in the research literature in expert-novice differences (Crandall et al. 2006). A series of well-developed questions which are based on extensive research on expert thinking form the focus of the knowledge audit (Militello and Hutton 1998; see Table 1). This stage of the ACTA is iterative and can take up to $2 \mathrm{~h}$ to complete, eliciting lived stories and scenarios from the experts being interviewed.

Finally, a Cognitive Demands table was completed by the engineers, providing an analytical summary of data elicited. The cognitive demand table is summary which provides an analysis of key aspects of expert cognition within the domain context and also clearly illustrates which aspects novices may find difficult. By documenting difficulties and capturing key cues and strategies for success, tacit knowledge is thus illustrated. In addition to providing training in the ACTA techniques, we also provided a briefing about theoretical issues in decisionmaking and an exercise to facilitate active listening and questioning skills, as most of the participants had not previously had experience of research-based interviewing and had a genuine interest in the theoretical roots of the CTA methods. All participants had no prior experience of intensive research-based interviewing and completed a questionnaire evaluation of their training experience. This questionnaire was developed aiming to evaluate cognitive, skill-based, and affective learning outcomes (Kraiger et al. 1993), providing construct-orientated evidence of validity. A peer evaluation of the application validity of the cognitive demands tables and training scenarios produced from the interviews was also completed in collaboration with experienced analysts. In addition, data were checked with other engineering experts to establish how far they agreed with the cognition elicited and most importantly how far they concurred that this tacit information was not currently available to novices. 
Table 2 Accessing expertise in the field: top tips for getting rich data/developing socio-cognitive competence/insight from ACTA

Redo and refine the task diagrams

Listen actively throughout

Stay focused and be clear about your roles

Bear with frustration

Ask what is difficult and ask about thinking

Do not assume and choose your pairings wisely

Remember that detail is good

Be aware of when you stop recording information

Use the crib sheets

Check your thinking
Retrace your steps and redo the task diagrams as needed-you may need several drafts to get the detail level right

ACTA works better if the interviewer listens actively: listen, summarise, and then record the information (rather than writing notes throughout, as you are more likely to miss key information, particularly for the knowledge audit)

Reign in the temptation to share anecdotes, this can distract from the task, and remain clear about how interviews and who is interviewer (rather than inadvertently swopping during the process)

The process might entail some frustration about taking too long, or not getting the right level of detail-this is completely normal! If in doubt or getting too tired, leave the task for a while, and come back to it the next day

One of the key objectives for ACTA is to highlight what experts think, but might not have shared explicitly. So do not be shy to clarify, ask for more detail, or ask questions again in a different way. Your data should tap into thinking (so go beyond obvious outcomes)

You might think that things are obvious (as interviewer or interviewee), but chances are that they are not. It can work well to work in pairs or triads who do not usually work with each other, rather than pairing up with close colleagues. This will allow you to ask important questions which team members may not ask, assuming that the answers should be obvious (they usually are not!)

As a rough rule of thumb, each component of your task diagram should be annotated with detail, and each aspect of the knowledge audit should fill about half a flip chart page

If there is a time in the interview when you talk, but no information is recorded on the flip charts, then ask yourself 'why'. Are you not asking the right questions? Have you gone 'off track'?

ACTA works best with structure, so do not be shy to use the crib sheets

Do talk each other through your diagrams and knowledge audits again, for instance clarify anything which is not clear, and make sure that the examples are specific, rather than general

\section{Results}

Our in situ training observations paired with the feedback evaluations gathered at the end of each training day show that the engineers found the process of interviewing and being interviewed using the ACTA techniques initially both cognitively and emotionally challenging. The socio-cognitive capabilities of the interviewer as facilitator of cognitive knowledge elicitation, and the interviewee, to take time to reflect in a thoughtful, reflexive, meaningful and organised way, were key to the success of the interviews. As an example, we observed how and then sensitively questioned why some of the ACTA outputs, including the task diagrams and knowledge audits, were more truncated and less nuanced for one sub-group of participants than for others having taken less time to complete during the training on day 2. During follow-up questioning at the end of the training day, the interviewee felt confident that they had participated, and given 'robust' information, the interviewee implied that answers had been monosyllabic and at points condescending, giving a little insight into actual expert cognitions. They attributed this to a perceived difference in status and seniority between the parties involved, as well as an (implicit) attitude on behalf of the interviewee that their mere presence had been enough. In contrast, we observed other dyads with richer outputs, where the interview process was a two-way and constructive. Questioned at the end of the first interview period, all participants found the training involved a great deal of focus requiring regular breaks to counteract fatigue, and that a key mechanism for counteracting such fatigue was the interviewer's skill to vary questions to sensitively probe information, as well as summarising the information at key points which helped both parties to ensure that key information had been understood and accurately recorded. They also voiced that whilst they found the briefing on socio-cognitive factors as well as general interview and feedback guidance informative, they would have appreciated a 'crib sheet' for how exactly they could implement and embed this guidance in the ACTA technique as such.

As a result of these observations, the authors and engineers co-created innovative practice guidance, shown in Table 2, to maximise the task diagram and knowledge-elicitation phase of ACTA and recognise the importance of socio-cognitive competence/insight. This innovation assisted participants and added to the language and positive social context for knowledge transfer, providing assurance and reference for best practice. This guidance sheet openly acknowledged the perceived difficulty, but also occasional frustration of the ACTA process, which helped to normalise that these are inherent features of a challenging processes, 
Table 3 Illustrative cognitive demand table for plant trials/start-up

\begin{tabular}{|c|c|c|c|}
\hline Difficult cognitive element & Why difficult? & Common errors & Cues and strategies used \\
\hline Effective communication & $\begin{array}{l}\text { Maximising information } \\
\text { sources requires effort and } \\
\text { maintenance } \\
\text { Sorting important informa- } \\
\text { tion from nice-to-have } \\
\text { Possible language barrier }\end{array}$ & $\begin{array}{l}\text { Excessive focus on one direct contact } \\
\text { Neglecting applications engineers }\end{array}$ & $\begin{array}{l}\text { Get involved in operator training } \\
\text { Get out and about, talk to operators, and } \\
\text { analytical chemists } \\
\text { Regular e-mail summary update to } \\
\text { customers/interested parties }\end{array}$ \\
\hline Planning ahead/sticking to plan & $\begin{array}{l}\text { Time-consuming and tedious } \\
\text { Misplaced fear of corrective } \\
\text { feedback to published plan } \\
\text { Concern about "planning for } \\
\text { failure } \\
\text { Plant may want to complete } \\
\text { trial to return to regular } \\
\text { production }\end{array}$ & $\begin{array}{l}\text { Inadequate plan } \\
\text { Fail to document possibility of unex- } \\
\text { pected events } \\
\text { Tendency to panic when faced with a } \\
\text { "surprise" } \\
\text { Inadequate sampling schedule } \\
\text { Not knowing when to be flexible }\end{array}$ & $\begin{array}{l}\text { Publish and agree in advance } \\
\text { Include "what if" scenarios and plan for } \\
\text { off spec product } \\
\text { "Phone a friend"- use all available } \\
\text { resources, collaboration } \\
\text { Over sample, no need to analyse all of } \\
\text { them } \\
\text { Send some samples to own lab } \\
\text { Apply full-testing schedule to first } \\
\text { batch, be flexible later if appropriate }\end{array}$ \\
\hline \multicolumn{4}{|l|}{ Technicals } \\
\hline $\begin{array}{l}\text { Compare plant samples with } \\
\text { lab programme } \\
\text { Test property trend } \\
\text { Challenge analytical data } \\
\text { DCS constraints } \\
\text { Commissioning }\end{array}$ & $\begin{array}{l}\text { Too much control room time } \\
\text { Separating important data } \\
\text { Embarrassment factor } \\
\text { Believe briefing }\end{array}$ & $\begin{array}{l}\text { Don't visit unit/lab } \\
\text { Neglect logical analysis } \\
\text { Only look at numbers, not the samples } \\
\text { Underestimate complexity and risk } \\
\text { Wrong rotation direction }\end{array}$ & $\begin{array}{l}\text { Get out of the control room } \\
\text { Plot or tabulate data } \\
\text { Diplomacy } \\
\text { Get face-to-face contact } \\
\text { Ask to meet } \\
\text { Be present for the commissioning } \\
\text { testing }\end{array}$ \\
\hline
\end{tabular}

rather than due to deficiencies of the parties involved in the process.

The tasks covered by the managers/engineers varied according to their organizational role and included everything from plant trial management; complex decisions surrounded choice of experiments for fuel testing; running a new project; improving supply security; to preparing to meet a new customer.

The task illustrated here (see Table 3) is from an expert process engineers analysis of the key cognitive demands involved in the task of completing an "initial manufacturing plant trial start-up". When new petroleum additives are developed, teams of research engineers with professional expertise in chemistry and physics run pilot or 'start-up' trials within the manufacturing plant. This process has a high degree of risk associated with it, and can be expensive and time-consuming, in terms of both health and safety and continued product innovation success. Process and product development are also subject to unique legal confidentiality agreements in this area of engineering. The task of setting up and monitoring a plant trial, therefore, involves a high degree of macro-cognitive complexity within an NDM-type framework (Orasanu and Connolly 1993). The macro-cognitive complexity, i.e., "the cognitive adaptation to complexity" (Klein and Hoffman 2008), can involve several experts managing risk and uncertainty, making sense of their dynamic environment, with high stakes and shifting, ill-defined goals under time-pressured situations.
Each of the engineers reported that the knowledge elicited, including key cues for improving situation awareness, and scenario planning had rarely been documented in such a pragmatic way previously. As illustrated, the results of an independently completed cognitive demand table completed by an experienced CTA researcher were comparable to the engineers' interpretations (see Table 3) focussing upon the task of completing a petroleum development plant trial. Here, we see clear areas of cognitive complexity elicited by the ACTA method for the expert plant trial engineer including: effective communication; planning ahead (responding to action-feedback loops); noting key technical cues and strategies. This summary was completed after reviewing the outputs from the ACTA interviews with three of the expert participants. They used a content analysis-based approach to highlight the key features of the task discussed by the engineers. They checked their summary with other experts in the organization before presenting it for further refinement to be used within future training scenarios.

In addition to documenting task-specific mental models, detailed perceptions of cues, and strategies, an important feature which emerged to the surprise of the engineers was the importance of hot/sensory-based cognition. For example, several engineers described noticing peculiar smells in the mornings which resulted in adjusting the manufacturing process before the new petroleum additive was destroyed, making significant economic savings and avoiding potential hazards. The completed summary analysis/cognitive demand 
table was then later used as a base for developing computerbased training which captured the lived expert realities of successful organizational tasks. The scenarios developed included a wide range of operational decision-making procedures through to highly scientific and engineering tasks. Each scenario clearly documented representations of expert mental models and was also subject to peer review from other expert engineering practitioners which assisted knowledge transfer.

Feedback from within the organization has been positive with the practitioners wanting to utilise more CTA-based training to continue to support organizational learning. The evaluation of the training suggested that the majority of participants felt that the ACTA techniques were "a very effective and efficient framework for helping articulate how experienced colleagues do specific tasks, provided structured learning and clear training outcomes". One participant, however, suggested that applying ACTA may be problematic in terms of "drilling down to the right level of granularity of a task to access the most specific tacit knowledge".

\section{Discussion}

Undertaking ACTA, examining its underpinning principles and evaluating its effectiveness require a longitudinal approach which with this study that we begin to offer. We demonstrate that ACTA is a promising vehicle to support knowledge management and transfer, and that, even with relatively short instruction time, practitioners can avail themselves of the technique and apply it in a peer-to-peer context. We reflect that an action-research centric paradigm is essential, however, as the observations on this case studybased research elicit that the emotional and socio-cognitive aspects of ACTA are important, and need to be facilitated and legimitised through relevant and tailored support. As the in-depth interview techniques are intensive and access System 2 thinking/cognition [slow, controlled, and analytical processing (Kahneman and Klein 2009)] to reflect upon System 1 thought/cognition processes (characterized by fast, heuristic-based, and emotional processing), careful interpretation, and mentoring and training are required.

We note as a limitation of the present paper that it was beyond its scope to undertake a truly longitudinal evaluation to determine and apply an internal and/or external benchmark to verify to what extent knowledge management as well as training and induction for novices had been improved. We also wish to emphasise that findings of the substantive content of the knowledge elicited by the engineers were not the primary aim of this paper and that the results presented are limited illustrations. What is important here is the contribution to training and improving training in general for practitioners (and potentially students) who wish to use ACTA techniques to reflect upon and elicit their expertise.

\section{Conclusion}

This work is original in its application as a few studies document such applied inclusion of practitioners in the co-construction of knowledge. The study demonstrates the utility of applying ACTA to the domain of utilities management and engineering in a macrocognitive framework through the elicitation of scenarios to assist novice engineering professionals. In turn, these will serve to raise situational awareness in relation to specific tasks and clearly define cognitive complexity in an organizational-based repository of training scenarios.

Our contribution to the development of CTA methods and knowledge management impact here strongly highlight the importance of recognising, managing, and providing training which supports practitioners to develop their socio-cognitive competence and insight, alongside knowledge elicitation documentation and transformative knowledge management solutions. The utility of CTA is ultimately dependent on the human capacity to elicit and articulate expertise, it is our contention that increased emphasis needs to acknowledge the potential intellectual and interpersonal challenges involved in this process. The complexities for resulting knowledge transfer provide an interesting research agenda with a range of potential theoretical and pragmatic contributions. (Grossman et al 2014; Salas et at 2015). Theoretically, exploration of the links between developing the reflexive System 2 thinking that the ACTA techniques require to reflect upon System 1 thinking offers an exciting research agenda; future studies might address this by taking a comparative approach to distil which elements of ACTA are particularly effective in this context, and how practitioners can best be supported in the application of relevant techniques. We hope that other researchers adapt and adopt the process offered in this paper and thus contribute to the growing NDM literature, training, and understanding expertise.

Open Access This article is distributed under the terms of the Creative Commons Attribution 4.0 International License (http://creativeco mmons.org/licenses/by/4.0/), which permits unrestricted use, distribution, and reproduction in any medium, provided you give appropriate credit to the original author(s) and the source, provide a link to the Creative Commons license, and indicate if changes were made. 


\section{References}

Anderson N (2007) The practitioner-research divide re-visited: strategic-level bridges and the role of IWO psychologists. J Occup Organ Psychol 80:2,175-183. https://doi.org/10.1348/09631 7907X187237

Briner RB, Rousseu D (2011) Evidence-based I-O psychology: not there yet but a little nearer? Ind Organ Psychol Perspect Sci Pract $14: 76-82$

Cannon-Bowers JA, Salas E, Converse SA (eds) (1993) Shared mental models in expert decision making. Ablex, Norwood

Cohen MS, Freeman JT, Wolf S (1996) Meta-recognition in time stressed decision making: recognizing, critiquing and correcting. Hum Factors 38(2):206-219

Crandall B, Klein G, Hoffman RH (2006) Working minds. MIT Press, Cambridge

de Groot AD (1978) Thought and choice in chess. Mouton, New York. (Original work published 1946)

Dreyfus HL, Dreyfus SE (1986) Mind over machine: the power of human intuitive expertise in the era of the computer. Free Press, New York

Drury JL, Darling E (2008) A 'thin-slicing' approach to understanding cognitive challenges in real- time command and control. J Battlef Technol 11:9-16

Endsley MR (1995) Measurement of situation awareness in dynamic systems. Hum Factors 37(1):65-84

Ericsson. KA, Smith J (1991) Towards a general theory of expertise: prospects and limits. MIT Press, Cambridge

Feltovich PJ, Ford KM, Hoffman RR (eds) (1997) Expertise in context. MIT Press, Menlo Park

Glaser R, Chi MTH (1988) Overview. In: Chi MTH, Glaser R, Farr MJ (eds) The nature of expertise. Lawrence Erlbaum Associates, Hillsdale

Goffee R, Jones G (2007) Leading clever people. Harv Bus Rev 85(3):72-79, 142

Gore J (2004) Mapping expertise in management: applied cognitive task analysis. In: Proceedings of the British Academy of Management Conference, Strathclyde

Gore J (2013) Transforming knowledege: capturing engineers' cognitive expertise. In: Proceedings of the 11th international conference on naturalistic decision making, Mareseill, France

Gore J, Conway GE (2016) Modeling and aiding intuition in organizational decision making: a call for bridging academia and practice. Appl Res Mem Cognit 5(3):331-334

Gore J, McAndrew C (2009) Accessing expertise. Psychol 22(3):218-219

Gore J, Riley M (2004) Recruitment and selection in hotels: experiencing cognitive task analysis. In: Montgomery H, Lipshitz R, Brehmer B (eds) How professionals make decisions. Lawrence Erlbaum, New Jersey, pp 343-350

Gore J, Ward P (Eds) (2017) Naturalistic Decision Making and Uncertainty: Proceedings of the 13th Bi-Annual Naturalistic Decision Making Conference. University of Bath, UK. ISBN 978-0-86197-194-7

Gore J, Banks A, McDowall A (2015a) Advancing ACTA: developing socio-cognitive competence/insight. In: Proceedings of the 12th International Conference on Naturalistic Decision Making. Washington

Gore J, Flin R, Stanton N, Wong W (eds) (2015b). Special issue applications of naturalistic decision making. J Occup Organ Psychol 88:223-386

Gore J, Flin R, Stanton N, Wong W (2015c) Applications for naturalistic decision making. J Occup Organ Psychol 88:223-230

Grossman R, Spencer JM, Salas E (2014) Enhancing Naturalistic decision making and accelerating expertise in the workplace: training strategies that work. In: Highhouse S, Dalal R, Salas E (eds) Judgment and decision making at work. Routledge, New York

Hoffman RR (1992) The psychology of expertise: cogntive rsearch and empirical A.I. Springer, New York

Hoffman RR, Militello LG (2008) Perspectives on cognitive task analysis: Historical origins and modern communities of practice. Taylor \& Francis, New York

Hoffman RR, Trafton G, Roebber P (2006) Minding the weather: how expert forecasters think. MIT Press, Cambridge

Hoffman RR, Ward P, Feltovich PJ, Dibello L, Fiore S, Andrews DH (2014) Accelerated expertise. Psychology Press, New York

Kahneman D, Klein GA (2009) Conditions for intuitive expertise: a failure to disagree. Am Psychol 64(6):515-526

Kahneman D, Tversky A, Slovic P (eds) (1982) Judgment under uncertainty: heuristics and biases. Cambridge University Press, Cambridge

Klein GA (1997) Developing expertise in decision making. Think Reason 3(4):337-352

Klein GA, Crandall B (1995) The role of mental simulation in naturalistic decision making. In: Hancock J, Flach J, Caird J, Vincente $\mathrm{K}$ (eds) Local applications of the ecological approach to humanmachine systems. Lawrence Erlbaum, Hillsdale, pp 324-358

Klein GA, Hoffman RR (1993) Seeing the invisible: Perceptual/cognitive aspects Of expertise. In: Rabinowitz M (ed) Cognitive science foundations of instruction. Lawrence Erlbaum, Mahwah, p 203226

Klein G, Hoffman R (2008) Macrocognition, mental models, and cognitive task analysis methodology. In: Schraagen JM, Militello L, Ormerod T, Lipshitz R (eds) Naturalistic decision making and macrocognition. Ashgate, Hampshire, pp 57-80

Klein GA, Calderwood R, MacGregor D (1989) Critical deciions methods for elicitink knowledge. IEEE Trans Syst Man Cybern (19):462-472

Klein GA, Orasasnu J, Claderwood R, Zsambok CE (eds) (1993) Decision making in action: models and methods. Ablex Publishing Corporation, Norwood

Koehler DJ, Harvey N (2004) Expertise in judgement and decision making: a case for training intuitive decision skills in. In: Blackwell handbooks of experimental psychology: blackwell handbook of judgement and Decision making. Blackwell, London

Kraiger K, Ford JK, Salas E (1993) Application of cognitive, skillbased, and affective theories of learning outcomes to new methods of training evaluation. J Appl Psychol 78(2):311-228

McAndrew C, Gore J (2010) Convince Me... An inter-disciplinary study of NDM and investment managers. In: Mosier K, Fischer $\mathrm{U}$ (eds) Experts in complex situations transforming information into knowledge. Psychology Press, New York

McAndrew C, Gore J (2012) Understanding preferences in experiencebased choice: a study of cognition in the wild. J Cognit Eng Decis Mak 3(2):156-175

McAndrew C, Gore J (2013) Understanding preferences in experiencebased choice: a study of cognition in the wild. J Cognit Eng Decis Mak 7(2):179-197

McAndrew C, Gore J, Banks A (2009) 'Convince me': modelling naturalistic decision making. J Cognit Eng Decis Mak 3(2):156-175

Militello LG, Hutton RJB (1998) Applied cognitive task analysis (ACTA): a practitioner's toolkit for understanding cognitive task demands. Ergonomics 41(11):1618-1641. https://doi. org/10.1080/001401398186108

Militello LG, Hutton RJB, Miller T (1997) Applied cognitive task analysis (computer software). OH Klein Associates, Fairborn

Militello LG, Wong W, Kirsechenbaum SK, Patterson E (2010) Systematizing discovery in cognitive task analysis. In: Mosier KL, Fischer UM (eds) Informed by knowledge: expert performance in complex situations. Taylor and Francis, New York, pp 23-40 
Orasanu J, Connolly T (1993) The reinvention of decision-making. In: Klein GA, Orasanu J, Calderwood R, Zsambok CE (eds) Decision making in action: models and methods. Ablex, Norwood, pp 3-20

Osland JS (2010) Expert cognition and sense-making in the global organization leadership context: A case study. In: Fischer UM, Mosoer KL (eds) Informed ny knowledge: expert performance in complex situations. Taylor and Francis, New York, pp 23-40

Osland J, Oddou A, Bird A, Osland A (2013) Exceptional global leadership as cognitive expertise in the domain of global change. Eur J Int Manag 7:517-534

Potworowski G, Green LA (2016) Training change agents in CTA to bring health care transformation to scale: The case of primary care practice facilitators. J Cognit Eng Decis Mak 11(4):328-349

Roth E (2008) Uncovering the requirements of cognitive work. Hum Factors 50(3):475-480

Salas E, Rosen MA, DiazGranados D (2015) Naturalistic decision making in indviduals and teams. In: Kozlowski SWJ (ed) Oxford handbook of industrial and organizational psychology. Oxford Univeristy Press, New York
Schraagen JM, Chipmam SF, Shalin VL (2000) Cognitive task analysis. Psychology Press, New York

Schraagen JM, Militello L, Ormerod T, Lipshitz R (Eds) (2008) Naturalistic decision making and macrocognition. Ashgate Publishing Limited, Aldershot

Shanteau J (1985) Psychological characteristics of expert decision makers. Kansas State University, Kansas

Strauss O (1997) Coping with uncertainty: a naturalisitc decision making analysis. Organ Behav Hum Decis Process 69(2):149-163

Tofel-Grehl C, Feldon DF (2013) Cognitive task analysis-based training: A meta analysis of studies. J Cognit Eng Decis Mak 7:293-304

Ward P, Gore J, Hutton RJB, Conway G, Hoffman RR (2018) Adaptive skill as The Sine Qua non of expertise. J Appl Mem Cognit 7(1):35-50

Wilkinson A, Kupers R (2013) Living in the futures: how scenario planning changed corporate strategy. Harv Bus Rev 